\title{
The perpetrators of child sexual abuse in Queensland, Australia
}

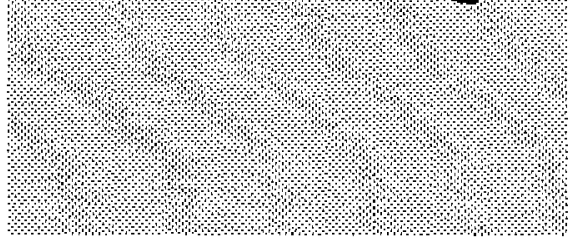

A retrospective study of 427 university students in Queensland, Australia, revealed that the majority of perpetrators of child sexual abuse were known to their victim. The rate of incestuous abuse before the age of 17 years was twice as high for females as for males. It was also much more likely that the respondent reported being abused by a male than a female, with stepfathers being one of the most frequently reported offenders. In contrast, strangers were found to perpetrate a minority of abuse. Consequently, recommendations are made for education programs in an effort to prevent children being abused by people whom they know and trust.

\author{
Juliette D.G. Goldman and Usha K. Padayachi
}

Most of the research into child sexual abuse and its perpetrators has emanted from the USA and Europe over the past 30 years (see Finkelhor, 1994). The only known published prevalence research undertaken in Australia has been that of Goldman and Goldman (1988a) and Goldman and Padayachi (1997), which used retrospective studies of university students in Victoria and Queensland respectively. While other Australian studies have been conducted, these have frequently been anecdotal (Mazza, Dennerstein \& Ryan, 1996) or drawn from offender or clinical populations (Briggs \& Hawkins, 1993). The present study examines the perpetrators of child sexual abuse in Queenslatid.

\section{LTTERATURE}

\section{PREPONDERANCE OF MALE PERPETRATORS}

The sexual abuse literature reveals a preponderance of male perpetrators (Finkelhor, 1979, 1982; Goldman \& Goldman, 1988a; Russell, 1984) and several researchers have explored explanations for this (Finkelhor \& Russell, 1984; Gilgun, 1991; Goldman \& Goldman, 1988b; Herman, 1981). One theory relates to sex role socialisation where women are socialised to confide or solve their problems through talking and discussing, whereas men are socialised to be inhibited about addressing their problems other than through aggression and dominance. Men appear to frequently link masculinity to sexual conquests and aggressiveness (Gilgun, 1991). Further, men who have been abused in childhood may also tend to act out their problems in sexual or sexually violent ways (Gilgun, 1991;
Herman, 1981). This is exemplified by Gilgun (1991) who found that of 36 maltreated male subjects, 15 were perpetrators of child sexual abuse and 12 were convicted of rape, attempted trurder, armed robbery and murter. None of the convicted felons reported that they disclosed their painful feelings to anyone.

A further example of such socialisation is seen in a study conducted in Brisbane, Australia, by the Domestic Violence Resource Centre (DVRC, 1992) which revealed that $33 \%$ of $14-$ year-old boys indicated they would hold a girl down and force her to have sex if she 'led him on'. Ten per cent of boys agreed that forced sex was acceptable if the couple had dated a 'long' time. A. large proportion of boys also believed that girls often said 'no' when they really meant 'yes'. A similar study conducted in the United States (Adams \& Fay, 1984) revealed that $39 \%$ of the high school boys surveyed thought it was okay to hold a girl down and force her to have sex if he spent a lot money on her, if she were drunk, or if she had sex with others. Furthermore, $36 \%$ of boys in that study said they would force a girl to have sex if he "just couldn't stop". These types of attitudes in boys indicate an early level of sexual aggression which may continue and lead to further sexual abuse when they are older.

\section{FEMALE PERPETRATORS}

Research indicates that women are less likely to sexually abuse children. Russell and Finkelhor (1984) found that, in the reported cases of child sexual abuse in the United States, less than $24 \%$ of female victims and $13 \%$ of male victims were abused by females. Similarly, Russell and Finkelhor's 
review of self-report studies reveals that of the male victims of child sexual abuse $27 \%$ or less were abused by women. One exception was a study by Fritz, Stall and Wagner (1981) who reported that $60 \%$ of the boys in their study were abused by women, a result that Russell and Finkelhor believe could have been due to an unusual sample or an error in tabulation.

For female victims in the self-report cases, studies typically report that fewer than $10 \%$ were abused by women (Finkelhor, 1984; Fritz et al., 1981; Fromuth, 1983; Russell, 1984), with the exception of two studies. Bell and Weinberg (1981) found that, of a sample of homosexuals, lesbians and heterosexuals, $22 \%$ of lesbians were abused by fernales. This may in part account for the high percentage of female perpetrators. It may also be that this percentage is not generalisable to all females. However, in another study, Finkelhor, Williams, Bums and Kalinowski (1988) found that $40 \%$ of the abusers in a day care setting were female. This unusually high incidence may be explained by the low presence of male workers in day care centres. Whatever the explanation, the figures from both these studies are considerably higher than many others. For instance, Russell (1984) reported $4 \%$, of abusers were female, Fromuth (1983) 5\%, Finkelhor (1984) 0\%, Finkelhor (1979) $6 \%$, and Fritz and associates (1981) $10 \%$.

Such data steadfastly support the claim that the overwhelming majority of perpettators are male (National Centre of Child Abuse and Neglect [NCCAN], 1981).

The present research aims to identify the perpetrators of child sexual abuse in Queensland. A sample of university students was asked to indicate if, as a child, they had experienced any unwanted sexual acts. If they had, then some characteristics of the perpetrators were investigated.

\section{METHOD}

\section{TERMS}

For purposes of this study, a child is defined as a person under the age of 17 years. The following definitions were also used.
- Child sexual abuse is defined as unwanted contact or non-contact sexual experience perpetrated on a child.

- Contact sexual abuse is defined as unwanted sexual experiences, including kissing, hugging or fondling a child's breasts or genitals; and/or simulated intercourse; and penetration of the vagina, anus, or mouth with a penis, finger or an object.

- Non-contact sexual abuse is defined as unwanted sexual experiences, including exhibitionism, taking picture of the child in the nude or engaging in sexual intercourse in the presence of the child.

- Incestuous or intrafamilial abuse includes any unwanted contact or non-contact sexual experience which is perpetrated on a child by a relative who is related to the child either by marriage or blood.

- Extrafamilial sexual abuse includes any unwanted contact or non-contact sexual experiences perpetrated on a child by individuals who are not relatives of the child (eg, authority figures, strangers, friends of family).

... women are socialised to confide or solve their problems through talking and discussing, whereas men are socialised to be inhibited about addressing their problems other than through aggression and dominance.

\section{SAMPLE}

The research design follows a model of tetrospective surveys on child sexual abuse previously undertaken in a number of western industrialised countries including the United States, Canda and Britain (Finkelhor, 1979; Goldman \& Goldman, 1988a; Goldman \& Padayachi, 1997). This survey was conducted in first year undergraduate classes at a major urban university in Brisbane which has a student population drawn from a relatively wide cross-section of Queensland families. Students were from a variety of academic major study areas, including psychology, sociology, social work, physiotherapy, human movement, engineering, medicine and law. As tertiary students, though, this may be regarded as a skewed sample relative to the general population.

A total of 427 students (140 males and 287 females) completed the anonymous questionnaire. The age range for male respondents was 17 to 49 years with a mean age of 21.1 years (SD=5.7). The age range for the female respondents. was 17 to 52 years with a mean age of 21.7 years $(\mathrm{SD}=7.9$ ). Approximately $89 \%$ of male respondents were single, $7 \%$ were married or in defacto relationships, and $4 \%$ were divorced or separated. By comparison, $81 \%$ of the female respondents were single, $12 \%$ were married or in defacto relationships and $7 \%$ were divorced, separated or widowed. A large proportion (78\%) of males were Australian in background, $13 \%$ were from a European family background, and three per cent were from a Chinese background. Similarly, $75 \%$ of females were Australian, $15 \%$ were from a European background, $3 \%$ were Chinese and $7 \%$ were from other minority ethnic backgrounds.

Approximately $33 \%$ of male and female respondents were Catholics, $25 \%$ were Anglicans, $14 \%$ were from the Uniting Church, $15 \%$ were from other Christian denominations and $12 \%$ were from other religious backgrounds.

\section{QUESTIONNAIRE}

The questionnaire was largely based on the one used by Finkelhor (1979) in this USA study and replicated by Goldman and Goldman $(1988 \mathrm{a}, 1988 \mathrm{~b})$ in Victoria, Australia. Finkelhor's questionnaire was modified to suit Australian society, as did Goldman and Goldman (1988a, 1988b). A modification made to Finkelhor's questionnaire was the inclusion of two additional types of sexual act, namely, taking pictures of the child in the nude and engaging in sexual activity in the child's presence (Goldman \& Padayachi, 1997; Padayachi, 1994). 
This was considered necessary, especially as taking a child's picture in the nude is considered child pornography and thus a form of child sexual abuse. For an analysis of methodological problems in child sexual abuse research, see Goldman and Padayachi (2000).

Respondents were asked to indicate if, as a child, they had experienced someone engaging in any of the following unwanted sexual acts:

\section{Experience Type 1}

a) took nude pictures of the child

b) exposed sexual organs to the child

c) engaged in sexual activity in the child's presence

\section{Experience Type 2}

d) kissed the child in a sexual way

e) hugged the child in a sexual way

f) touched or fondled the child's breasts and/or genitals

Experience Type 3

g) made the child touch or fondle their (perpetrator's) breasts and/or genitals

\section{Experience Type 4}

h) attempted to insert a penis in the child's vagina and/or anus

i) attempted to insert something else (finger or object) in the child ${ }^{*} s$ vagina and/or anus

\section{Experience Type 5}

j) inserted a penis in the child's vagina and/or anus

k) inserted something else (finger or object) in the child's vagina and/or anus.

\section{Sample groups}

Completed questionnaires were grouped into those who had been sexually abused and those who had not. Of the 287 females sampled, 128 (45\%) selfclassified as sexually abused as a child. Of the 140 males sampled, 26 (19\%) self-classified similarly. The following analysis addresses only those 154 who self-classified as sexully abused.

\section{Statistical analysis}

Data were analysed using the Statistical Package for the Social Sciences (SPSS$\mathrm{PC}$ v7). Statistical significance was set at the .05 level.

\section{RESULTS}

\section{PERPETRATORS OF CHILD SEXUAL ABUSE}

Respondents who reported unwanted sexual experiences were asked to indicate the sex of the perpetrator, and the perpetrator-victim relationship. For the perpetrator-victim relationship, the relationship categories were:

a) relative, including father, stepfather, mother, stepmother, brother, sister, uncle, aunt, stepbrother, stepsister, grandfather, grandmother, cousin and any other relatives;

b) someone in authority, including teacher, childminder, employer, member of clergy, doctor, and other persons in positions of trust;

c) strangers;

d) family friends;

e) friends of the victim.

Table 1 presents the perpetrator/victim relationship for male and femaje victims. A total of 156 unwanted sexual experiences were reported by 115 females, and 27 unwanted sexual experiences were reported by 24 males. Forty-eight per cent $(n=13)$ of the unwanted sexual experiences reported by males, and $34.6 \%(\mathrm{n}=54)$ of those reported by female victims were incestuous. Approximately $8 \%(n=2)$ of the male victims and $14 \%(n=18)$ of female victims reported abuse by both relatives and non-relatives. Strangers tended to be proportionately more sexually predatory toward males with about $22 \%$ of males and $14 \%$ of females reporting sexual experiences with people who were unknown to them. These figures are slightly lower than the $30 \%$ of boys and $24 \%$ of girls reported by Finkelhor (1979). Most of the experiences reported by the victims in the current study were with relatives, family friends or friends of the victin. These results confirm past findings that most perpetrators are known to their victims.

Of those who indicated who their perpetrators were, $27 \%$ of them were abused by perpetrators from two or more different categories with $20 \%$ $(n=23$ ) reporting abuse by two perpetrators, $5 \%(n=6)$ by three perpetrators, and nearly $2 \%(n=2)$ by four perpetrators from four different categories. Only $12 \%(\mathrm{n}=3)$ of male victims indicated abuse by perpetrators from two different categorics. These findings clearly indicate that female

Table 1 Number of sexual abuse experiences by perpetrator-victim relationship

\begin{tabular}{|c|c|c|c|c|}
\hline \multirow{3}{*}{ Relationship } & \multicolumn{4}{|c|}{ Number of sexual abuse experiences reported by: } \\
\hline & \multicolumn{2}{|c|}{ Male } & \multicolumn{2}{|c|}{ Female } \\
\hline & $\mathrm{n}$ & $\%$ & n & $\%$ \\
\hline Relative & 13 & 48.1 & 54 & 34.6 \\
\hline Someone in authority & 1 & 3.7 & 8 & 5.1 \\
\hline Stranger & 6 & 22.2 & 22 & 14.1 \\
\hline Family friend & 4 & 14.8 & 39 & 25.0 \\
\hline Friends of victims & 3 & 11.1 & 33 & 21.2 \\
\hline Total experiences reported & 27 & & 156 & \\
\hline Persons reporting* & 24 & & 115 & \\
\hline $\begin{array}{l}\text { Total number of persons } \\
\text { reporting sexual abuse }\end{array}$ & 26 & & 128 & \\
\hline \multicolumn{5}{|c|}{$\begin{array}{l}\text { * Two male and } 13 \text { female respondents did not indicate who their perpetrators were. } \\
\text { * Respondents indicated relationships for all experiences before age } 17 \text {. If a } \\
\text { respondent indicated abuse by different categories of perpetrators, they were counted } \\
\text { for each one. Therefore, column does not sum. }\end{array}$} \\
\hline
\end{tabular}


Table 2 Incestuous abuse by type of perpetrator

\begin{tabular}{|c|c|c|c|c|}
\hline \multirow[t]{2}{*}{ PERPETRATORS } & \multicolumn{2}{|c|}{ No. of experiences reported by } & \multicolumn{2}{|c|}{ Percentage in sample } \\
\hline & Males & Females & Males & Females \\
\hline Father & 5 & 19 & 3.6 & 6.6 \\
\hline Steptather & 3 & 7 & 2.1 & 2.4 \\
\hline Mother & 1 & 5 & 0.7 & 1.7 \\
\hline Stepmother & 1 & 2 & 0.7 & 0.7 \\
\hline Grandfather & 1 & 6 & 0.7 & 2.1 \\
\hline Grandmother & 0 & 0 & 0.0 & 0.0 \\
\hline Brother (step, biological) & 3 & 8 & 2.1 & 2.8 \\
\hline Sister (step, biological) & 0 & 3 & 0.0 & 1.0 \\
\hline Uncle & 1 & 15 & 0.7 & 5.2 \\
\hline Aunt & 0 & 1 & 0.0 & 0.3 \\
\hline Cousins & 0 & 7 & 0.0 & 2.4 \\
\hline Other relatives & 0 & 2 & 0.0 & 0.7 \\
\hline $\begin{array}{l}\text { No. of experiences } \\
\text { reported }\end{array}$ & 15 & 75 & & \\
\hline $\begin{array}{l}\text { No. of persons reporting } \\
\text { incest }^{*}\end{array}$ & 13 & 54 & & \\
\hline $\begin{array}{l}\text { Per cent in abused } \\
\text { sample group }\end{array}$ & $54.2 \%$ & $47.0 \%$ & & \\
\hline Per cent in total sample & $9.3 \%$ & $18.8 \%$ & & \\
\hline \multicolumn{5}{|c|}{$\begin{array}{l}\text { If a respondent was abused by one relativebut on a number of occasions, it was } \\
\text { counted as one experience. However, if he or she was abused by more than one } \\
\text { relative, they were counted for each one, thus column does not sum. } \\
\text { Two males and thirteen female victims did not indicate who their perpetrators were, } \\
\text { thus the percentages were calculated out of } 24 \text { male victims and } 115 \text { female victims } \\
\text { who had reported about their perpetrators. }\end{array}$} \\
\hline
\end{tabular}

victims of sexual abuse are more often abused by multiple perpetrators than are males.

\section{INCESTUOUS CHID ABUSE}

Table 2 shows that about $54 \%$ of the males and $47 \%$ of the fernale victims reported at least one experience of incestuous abuse before the age of 17 . These figures indicate that a slightly larger proportion of rale victims than female viotims were abused by their relatives. However, further analysis reveals that females were more often abused by more than one relative. Some $18.8 \%(\mathrm{n}=54)$ of all fernales sampled reported a total of 75 incestuous experiences. In comparison, $9.3 \%$ $(n=13)$ of all males reported a total of 15 incestuous experiences. Thus, the prevalence rate of incestuous abuse of females is twice as high as for males.

\section{FEMALE PERPETRATORS OF INCEST AND KINDS OF SEXUAL ACTIVTTIES}

Females constitute a small minority of incestuous abuse perpetrators when compared to the preponderance of male perpetrators. Sexual abuse by female relatives $(n=13)$ accounts for about $14 \%$ of all incest reported. However, this rate is three and a half times higher than Russell's (1984;1986) finding that females were the perpetrators in only $4 \%$ of incest. Thus, it is less likely for children to be sexually abused by female relatives than by male relatives.

Mothers (inciuding stepmothers) appear to be more likely to sexually abuse their children than any other female relative. Unwanted sexual experiences with biological mothers were reported by $4 \%$ $(n=5)$ of all female victims of incest.
Three of these victims were also abused by their stepfathers or biological fathers. This suggests that some mothers may have collabotated with fathers or father figures to abuse the victim. One male victim reported his mother fondled his genitals when he was eight years old. All the victims who were abused by their toothers were nine years of age or younger at the time of abuse. Unwanted sexual abuse by stepmothers was reported by two females and one male. Only one female reported a sexual experience with an aunt. Not a single case of abuse by a grandmother was reported. The sexual activities reported as perpetrated by females were mainly kissing and fondling, except in two cases where a stepmother and a stepsister had digital intercourse with a stepdaughter and a stepsister, respectively.

\section{EXTRAFAMULIAL ABUSE}

Approximately $7.9 \%(n=11)$ of males and $26 \%(n=74)$ of females in the total sample reported at least one incident of extrafarnilial child sexual abuse. The proportion of females abused by nonrelatives is more than three times higher than for males. Moreover, females are abused more often by multiple perpetrators, with 74 female victims reporting a total of 102 extrafamilial experiences. Thus, it is not uncommon for female victims to be abused by a number of non-relatives. In comparison, 11 male victims reported 14 extrafamilial experiences.

\section{DISCUSSION}

\section{PERPETRATOR-VICTIM RELATIONSHIP}

The tesults show that $48 \%$ of perpetrators who abused male children were relatives of the child, about $30 \%$ were authority figures or friends of family and victim, and $22 \%$ were strangers, In contrast, of the perpetrators who abused fernale victims $35 \%$ were relatives, $51 \%$ were acquaintances and $14 \%$ strangers.

The prevalence rate of $18.8 \%$ for the incestuous abuse of females concurs with Russell's (1984;1986) 16\%. These rates, however, are substantially lower than Finkelhor's (1979) $28 \%$ for fernales and $23 \%$ for males. The difference may be explained by Finkelhor's non-differentiation between 
wanted and unwanted sexual experiences. Thus, wanted sexual experiences may have inflated Finkelhor's rates.

\section{PERPETRATORS OF INCEST}

Nine per cent of males and $19 \%$ of females reported at least one experience of incest before the age of 17 years. These findings indicate that incest is not uncommon (See De Maus, 1991). The father-son incest rate of $5.7 \%(n=8)$, including three cases of sexual abuse with stepfathers, provides evidence of the sexual abuse of boys by their fathers. The father-daughter incest rate of $9 \%(n=26)$, including seven cases of abuse by stepfathers, is twice the rate reported by Russell (1984). Other male relatives, including uncles, grandfathers and siblings were also likely perpetrators of sexual abuse. Thus, the popular stereotypes that 'stranger danger' poses the most serious risk are not supported in this survey.

\section{PREPONDERANCE OF STEPFATHERS AS PERPETRATORS}

Stepfathers appear to be more sexually predatory than any other relatives, considering the fact that only $8 \%$ of males and $7 \%$ of females reported having a stepfather. According to Finkelhor's (1984) 4-part model, explanations for the preponderance of stepfathers as perpetrators of incest may include the following.

- Weak parent-child bond Finkelhor (1984) proposed that one of the four preconditions that needs to be fulfilled before child sexual abuse occurs is that the adult must overcome his or her internal inhibitions against acting out sexual feelings. Further, according to a bio-social theory of incest avoidance, physical and psychological distance from the child during the early years increases the probability of incest Parker, 1976, 1984; Parker \& Parker, 1986) while familiarity with the child reduces sexual arousal in the parent. In this study, those respondents who indicated they had stepfathers largely reported that they were in their pre-pubertal years (approximately 7 years) when the stepfather joined the family. Thus, the lack of opportunity for bonding appears to lessen stepfathexs' internal inhibitions against sexual acting out with their stepdaughters. Thus, stepfathers tend to be more sexually predatory than biological fathers.

... most perpetrators are

known to the victims. Children need to be protected, not only from strangers, but from family members, relatives and others in the community, regardless of age, gender, authority and social class.

\section{- Weak incest taboo}

Since stepfathers and stepchildren are not biologically related, the cultural taboo against sexual relationships between them is not as stringent. This may lessen stepfathers' inhibitions against abusing their stepchildren. However, as De Maus (1991) has pointed out, the alleged incest taboo needs to be challenged because there is widespread incest in most societies in most times.

\section{- Non-intact families}

According to Finkelhor (1984) another precondition for sexual abuse is that the adult must overcome external obstacles. Since non-intact families or families with stepfathers are frequently disjointed greater opportunity may be available for predatory stepfathers to contrive situations where they are alone with a stepdaughter in the house or elsewhere for long, uninterrupted periods. Thus, the disjointed nature of stepfamilies may to some extent contribute to the high vulnerability of girls to sexual abuse by stepfathers.

- Lack of resistance from the child Finkelhor (1984) also suggests that the adult must overcome resistance from the child to sexually abuse him or her. The daughter in a reconstructed family may not receive as much attention after her mother has remarried, or she may feel betrayed by her mother. Consequently, she may seek attention or affection from her stepfather which otherwise may not be available. This quest may be misconstrued as sexual gestures by her stepfather. Any or a combination of these factors may make her vulnerable for abuse by her stepfather.

\section{PERPETRATORS OF EXTRAFAMTLIAL ABUSE}

The results of this survey show that of the male victims of extrafamilial sexual abuse, $43 \%$ reported sexual experiences with strangers, $29 \%$ with family friends, and $21 \%$ with their own friends. In comparison, of all the female victims of extrafamilial sexual abuse, $21 \%$ reported sexual experiences with strangers, $38 \%$ with family friends and $32 \%$ with friends of the victim.

The results also reveal that children are more at risk of sexual abuse from their acquaintances than from strangers. For instance, $40 \%$ of all perpetrators who abused male children were acquaintances of the victims while $22 \%$ were strangers. In addition, $51 \%$ of perpetrators who abused female children were acquaintances of the victims compared to only $14 \%$ who were strangers. Russell (1984) reported that only $11 \%$ of the women in her study were abused by strangers compared to $24 \%$ reported by Finkelhor (1979). However, Russell inciuded only contact sexual experience. This may explain why the rate of sexual abuse by strangers was quite low as the present study shows that strangers normally engage in exhibitionistic display of genitals.

Moreover, it appears that males are proportionately more likely to be abused by strangers than are females. This may be because male children tend to be more independent and less closely supervised than females, thus making them more accessible to abuse by strangers. There may also be a link between particular types of perpetrators, victims and forms of abuse, and also a reluctance on the part of young males to report abuse. 


\section{PREPonderance of MALE PERPETRATORS}

Being a male in itself appears to be a significant predisposing factor for the tendency to sexually abuse childten, as $86 \%$ of all incest perpetrators, and all but three perpetrators of extrafamilial sexual abuse, were males. Evidence from other studies also indicate that males are the main perpetrators of child sexual abuse (eg, Finkelhor, 1979 , 1982; Fromuth, 1983; Goldman \& Goldman, 1988a; Goldman \& Padayachi, 1997; Russeil, 1984). Several explanations offered in the literature for the preponderance of male perpetrators, include the following.

\section{- Male serual drive}

The most popular image of masculine sexuality, seen as what Holloway (1984) calls the "male sexual drive discourse", is the notion that 'men's sexuality is directly produced by a biological drive, the function of which is to ensure the reproduction of the species' (p.231). If masculine sexuality is biologically predetermined, innately aggressive and active, then this implies that female sexuality is innately passive and inhibited. This view may be adopted by male perpetrators to justify their actions. However, the theory of 'men's sexual drive discourse' does not explain why some men take sexual advantage of children and others do not.

Consequently, several other factors deserve consideration.

\section{- Sex role socialisation}

Differences in sex role socialisation may explain why males are more sexually abusive toward children than females. Males may associate sexual conquests and aggressiveness with masculinity. Also, men who have been sexually abused as children tend to act out in sexual or sexually violent ways when adults. It is often believed that the victim becomes the victimiser to master the trauna he suffered. However, if this explanation is valid then there should be more female perpetrators since more girls are sexually abused than boys.

- Power structure

Finally, male dominance and the power structure in society may explatin why males are more sexually predatory than femaies. Males are perceived as more powerfil and are used to being obeyed by children and women. Thus, children, being the weakest and most vulnerable in the power structure, fall victin to male perpetrators.

\section{CONCLUSION}

The results of this study clearly demonstrate that most perpetrators are known to the victims. Children need to be protected, not only from strangers, but from family members, relatives and others in the community, regardless of age, gender, authority and social class. To curb this intolerable affront to children, a concerted effort by parents, educators and other professionals is needed (Wurtele \& Miller-Perrin, 1993). This should include strategies to minimise the vulnerability of cbildren (Briggs \& Hawkins, 1993). It should consist of parenting education, human relationships education, anti-sexual violence progranmes, sex education including appropriate sexual vocabulary, and sexual abuse education (Goldman, 1995; Goldman \& Goldman, 1982). Schools are certainly the most promising institutions for the development and delivery of such programmes for both children and parents (Goldman \& Goldman, 1982). As advocates for children, school counsellors and teachers are in key positions to provide an essential component in the intervention and prevention of child sexual abuse. However, the findings in a recent study (Goldtnan \& Padayachi, 2000) suggest there is also an urgent need for school counsellors, at least in the state of Queensland, to be trained further in areas relating to sexual abuse. Training programmes for educators, parents and counsellors in the prevention and treatment of sexual abuse should become a national priority to end this social crime against children. $\square$

\section{REFERENCES}

Adans, C. \& Fay, J. (1984) Nobody told me it was rape, Santa Cruz, CA: Network Publications.

Bell, A \& Weinberg, M. (1981) Serual preference: Its development among men and women, Bloomington, IN: Indiana University Press.

Briggs, F, \& Hawkins, R.M.F. (1993) 'Children's perceptions of personal safety issues and their vulnerability to molestation", Chiliren Australia, 18(3), 4-9.

De Maus, L. (1991) 'The universality of incest', Joumal of Pychohistory, 19(2), 123-164.

Domestic Violence Resource Centre (1992), AA report on the survey of ninc-year olds and their attitude to forced sex', Brisbane: Domestic Violence Resource Centre, September.

Finkelhor, D. (1994) 'The International Epidemiology of child sexual abuse', Child Abuse and Neglect, 18(5), 409-417.

Finkelhor, D. (1979) Sexually victimized chitdren, New York: Free Press.

Finkelhor, D. (1982) 'Sexual abuse: A sociological perspective", Child Abuse and Neglect, 6, 95-102.

Finkelhor, D. (1984) Child senual abuse: New theory and research, New York: Free Press.

Finkelhor, D. \& Russell, D. E. H. (1984) 'Women as perpetrators: Review of the evidence', in D. Finkelhor \& Associates (eds), Child sexual abuse: New theory and research, New York: Frec Ptess.

Finkelhor, D., Williams, L. M., Burns, N. \& Kalinowski, M. (1988) Sexual abuse in day care: $A$ national study, Family Research Lab: University of Hampshire, NH.

Fritz, G.S., Stall, K. \& Wagner, N.N. (1981) ‘A comparison of males and females who were sexually molested as children', Journal of Sex and Marital Therapy, 7, 54-59.

Fromuth, M.E. (1983) 'The long-term Psychological impact of childhood sexual abuse', Doctoral dissertation, Auburn University.

Gilgun, J.F, (1991) 'Resilience and the intergenerational tsanstrission of child sexual abuse', in M. Q. Patton (ed.), Family sexual abuse: Frontine research and evaluation, CA: Sage Publication the.

Goldman, J.D.G. (1995) All of me Sex education for juniors, Melboume, Australia: Longman

Goldman, R.J. \& Goldman, J.D.G. (1982) Children's sexual thinking, London: Routlodge \& Kegan Paul L.td.

Goldman, RJ. \& Goldman, J.D.G. (1988a) "The prevalence and nature of the child sexual abuse in Australia', Ausiratian Journal of Sex Marriage and Family, 9, 94-106.

Goldman, R.J. \& Goldman, J.D.G. (1988b) Show me yours: Understonding children's sexuality, Victoria: Penguin Books. 
Goldman, J.D.G. \& Padayachi, U.K. (1997) "The prevaleuce and nature of child sexual abuse in Queensland, Australia', Imternational Joumal of Child Abuse and Neglect, 21(5), pp 489-498.

Goldman, J.D.G. \& Padayachi, U.K (2000) 'Methodological problems in child sexual abuse research' (accepted).

Herman, J.L. (1981) Father-daughter incest, Mass: Harvard University Press.

Holloway, W. (1984) 'Gender difference and the production of subjectivity', in J. Henriques, W. Holloway, C. Urwin, C. Venn \& V. Walketdine (eds.), Changing the Subject, London: Methuen

Mazza, D., Dennerstein, L. \& Ryan, V. (1996) 'Physical, sexual and emotional abuse against women: A general practice-based prevalence study', Medical Journal of Australia, 164, 14-17.

National Centre on Child Abuse and Neglect (NCCAN) (1981), 'Study findings: National study of incidence and severity of child abuse and neglect', U.S. Department of Health and Human Services.

Padayachi, U.K (1994) 'The nature and prevalence of child senal abuse in Quectisland and school counsellors' responses", PhD thesis, University of Queensland, Australia.

Parker, S. (1976) 'The precultural bases of the incest taboo: toward a biosocial theory', American Anthropology, 78(2), 285-305.

Parker, S. (1984) 'Cultural rules, rituals, and behaviour regulation', American Anthropology, 86(3), 584-600.

Parker, H. \& Parker, S. (1986) 'Father-daughter sexual abuse: An enterging perspective', American Journal of Orlhopsychiatry, 54(4), 531-549.

Russell, D.E.H. (1984) Sextal exploitation: Rape, child sexual abuse, sexual harassment, Beverly Hills, CA: Sage.

Russell, D.E.H. (1986) The secret tratma: Incest in the lives of girls and women, New Yok: Basic Books.

Russell, D.E.H. \& Finkelhor, D. (1984) 'The gender gap among perpetrators of sexual abuse', in D.E.H. Russell (1984) Sexual exploitation: Rape, child sexual abuse, seralal harassment, Beverly Hills, CA: Sage.

Wurtele, S.K \& Miller-Perrin, C.L. (1993) Preventing child secual abuse: Sharing the responsibility, Lincoln, Nebraska: University of Nebraska Press.

\section{A REQUEST TO YOUNG PEOPLE IN FOSTER CARE, FOSTER CARERS AND SOCIAL WORKERS}

\author{
Dear Friends \\ YOUNG PEOPLE'S HOBBIES AND INTERESTS \\ HAVE THEY HELPED?
}

1 have been involved in foster care in different ways over the years - as a social worker, foster carer, board member of the Irish Foster Care Association, and as a researcher. It is as a researcher that 1 am writing to ask for your help.

I am looking for examples of how involvement in hobbies and interests may have helped some young people to do well growing up in foster care - or for the time they spent in a foster family. I am interested in collecting any stories of this kind. You can drop me a line by post - or even send me an email. Let me know about the activity or interest and how it helped. It might also be good to learn something about how the young person took up the interest or activity, and who or what encouraged or supported this. If you have seen ways in which hobbies and interests have been actually unhelpful, I am interested in hearing about that too. Just sending even a few lines explaining about the hobby and so on will be a great help.

I would appreciate it if you send me your address so that I can thank you and check something with you if I need to.

What will I do with the sackful of replies I will receive? I want to Write about the contribution that hobbies and interests can make (or not) to the well being of young people in foster care. There is nothing to beat the words and experience of people involved to make the point. So here's your chancell I am very pleased to acknowledge by name people who respond if they wish, but will respect people's privacy otherwise.

Thank you in anticipation. The post person is in special training here to prepare for the extra load of your lettersl if you give me your name and address I promise to write back to thank you.

Robbie Gilligan

Senior Lecturer in Social Work

Dept of Social Studies

Trinity College

University of Dublin

Dublin 2, IRELAND

Email: Robbie.Gilligan@tcd.ie 